Proc. IAHS, 377, 1-1, 2018

https://doi.org/10.5194/piahs-377-1-2018

(c) Author(s) 2018. This work is distributed under

the Creative Commons Attribution 4.0 License.

(c) (i)

\title{
Preface: Water quality and sediment transport issues in surface water
}

\author{
Gil Mahe ${ }^{1}$, Kate Heal ${ }^{2}$, Akhilendra B. Gupta ${ }^{3}$, and Hafzullah Aksoy ${ }^{4}$ \\ ${ }^{1}$ IRD, HydroSciences Laboratory, Montpellier University, Montpellier, France \\ ${ }^{2}$ The University of Edinburgh, School of GeoSciences, Edinburgh, Scotland, UK \\ ${ }^{3}$ Department of Civil Engineering, MNIT, Jaipur, India \\ ${ }^{4}$ Istanbul Technical University, Civil Engineering Faculty, Istanbul, Turkey \\ Correspondence: Gil Mahe (gil.mahe@ird.fr)
}

Published: 16 April 2018

Sediment transport and water quality are modified by human activities all along river courses. If research focuses only on pristine basins and large dams, little is known about the quality of the waters flowing to the sea. Most rivers around the world regulated to some extent by hydraulic infrastructure, even in developing countries. How river management impacts on water quality and sediment transport from the upper basins to coastal areas is not well known in many countries, especially in the developing world, even though this may have strong and longlasting effects on coastal geomorphology and ecosystems. In a time where many people try to explain the coastal recession that is observed on many coastlines, from the sea level rise and thus from "global change", knowledge of the actual sediment transport to the sea could bring new perspectives, as the reduction of riverine sediment transfer certainly contributes to this recession. One of the associated questions is what is the role of the human impact on these processes? At what speed do these changes take place?
This proceeding volume gathers together communications about water quality and sediment transport monitoring and modeling, especially for large river basins, with a focus on the relationships between estuarine river systems and coastal areas in terms of water quality and sediment load. There are also studies presenting diverse methods for estimating the amount of sediment released to the sea and its variability in time. All these papers were presented as oral or poster communications during the IAHS International Conference of Port Elizabeth, South Africa, July 2017. 